\title{
The Globalization of Higher Education - Be Responsible and Survive the Changes
}

\author{
Jaroslav Havlicek $^{1} \&$ Martin Pelikan ${ }^{1}$ \\ ${ }^{1}$ Faculty of Economics and Management, Department of Systems Engineering, Czech University of Life \\ Sciences Prague, Kamycka 129, Prague, Czech Republic \\ Correspondence: Martin Pelikan, Faculty of Economics and Management, Department of Information \\ Engineering, Czech University of Life Sciences Prague, Kamycka 129, Prague, Czech Republic. Tel: \\ 420-224-382-367. E-mail: pelikan@pef.czu.cz
}

Received: February 13, 2013 Accepted: February 26, 2013 Online Published: March 26, 2013

doi:10.5539/ies.v6n4p217

URL: http://dx.doi.org/10.5539/ies.v6n4p217

\begin{abstract}
The ongoing social changes taking place on a global scale have made universities respond to these new challenges by offering new study programmes, implementing modifications of study plans, taking up new research focus as well as by broadening the offer of adult education. These changes necessarily require modifications in terms of the structure and the style of management in university departments and institutes representing the most elementary university structure. In this article, a methodological analysis of university environment has been carried out as well as the identification of problems linked with the traditional styles of the central European university organization and management. Then follows the categorization of four styles of university management as they are recognized these days and subsequently the possibility of transforming the institutions of higher education into virtual universities (network universities) has been considered. Virtual (network) universities are most commonly associated with the styles of management encountered in enterprises and they are believed to be able to ensure the requirements as for the education of population in the environment of global society.
\end{abstract}

Keywords: global environment, central EU universities, management of higher education, descriptive and normative managerial styles, network university, "Nika" university

\section{Introduction}

The process of change as far as the strategy and the management employed at universities are concerned has been dealt with in a great number of expert works. A university is influenced by many factors such as quality of staff, location in the region, the attractiveness of educational programs, personnel and marketing management, relationships in the workplace, etc. These factors are significantly influenced by three factors when pursuing its activities - it is the threefold factor of economics, politics and technology. In a global society, economic influence becomes the least apparent; though the society try to become richer than earlier, universities tend to suffer from underfunding the same as it used to be in the past. Political influence is important especially in Central Europe where universities have been provided with valuable powers and they have become autonomous regarding their decision-making processes. Nevertheless, it is the influence of information and telecommunication technologies (ICT) accelerating the development of education and changing both its form and content in a particularly breath-taking way which has proved to be the most significant. But the huge development of ICT brings not only progress but also the risk of loss of individuality and uniqueness of the university environment: you can shave with a razor, or also cut.

The hyper-competitive, global, knowledge-driven economy of the 21 st Century stimulates the necessary changes of higher education. A university degree has become a necessity for most citizens. Higher education is desirable for the most of carriers. In the knowledge economy, the key asset driving corporate capital is no longer unskilled labour but intellectual and human capital.

The process of changes is more complex when taking place at universities than in production enterprises. Academicians have to implement the changes "hand in hand with everyday agenda", continuously and in a competitive environment. 
The article examines the most fundamental information from chosen specialist literature with respect to the influence exerted by the above mentioned factors, i.e. economic, politics (manifested especially in the legislative environment), and ICT technologies. The findings and conclusions of two important projects approached within the last two years are included: the Project of Comprehensive International Evaluation and the Project of a Long-term Development Vision of the Czech University of Life Sciences Prague until the Year 2020 (Harper, 2006; Havlicek, 2008; Shutt, 2005).

Until the end of the twentieth century, the ICT centres provided connection with population and their primary concern therefore was the one-way and top-down oriented communication directed from the centre to a man. However, today's communication networks have already begun to connect all objects and subjects on a reciprocal basis.

A man owning a cell phone or having internet connection is a centre that is connected with all other subjects occurring in the surroundings of his own choice; it thus involves the paradigm of a circle of infinite radius having its centre anywhere and lacking its perimeter. This scheme serves as well as the prospective model of virtual education and it implies the way the education in a global society will be implemented in the future. Thus, the role of ICT should be pursued in almost all areas of academic life (Duderstadt, 2004). On the one hand, a person connected to the Internet or holding the mobile becomes the centre of the universe, on the other hand, he/she increases the information noise. This results in an increase of ballast on the Internet, but it also bothers us in vehicles where people are screaming into mobiles, regardless of passengers.

The article aims to conduct an analysis of economic and political environment as well as its influence on university education within the frame of globalizing economies. It simultaneously aims to provide a proposition of measures leading to the transformation of both management structure and style of university departments so that they would become able to compete on education market in a global world and have kept traditional university values.

Authors processed and analysed the information sources presented in scientific articles, documents on strategies of renowned universities abroad, European White Papers. Conclusions ensuring from SWOT, round table debates and information acquired when solving the development projects were exploited, too (Zuboff, 1998).

\section{Managerial Problems at the University}

\subsection{The University as Learning Organisation}

University operates in an environment considerably different from the standard environment of a production enterprise or an organization. There are various individual goals, various solutions of the same problem and individual interests on departments which dispose of rather high degree of autonomy. In terms of team decision-making, academicians tend to be rather obstinate as partners and as experts they try to enforce partial goals.

Paradoxically enough, the concept of a "learning organization" is very hard to transform inside into an university although it is a "learning university".

It makes part of academic culture and university teachers are expected to complete their education on a continuous basis by studying specialist literature - not only in the field of their specialization but also in the area of general education. This study, however, cannot make up for the content that is presented to employees in a "learning organization". It is even the university that should behave like a "learning organization" and implement corporate education that it offers to others within its own environment (Havlicek et al., 2006).

\subsection{Lack of Managerial Skills in Departments}

The most fundamental university workplace is represented by departments being directly involved in research and the provision of education in the field of managerial disciplines. They are responsible for the education and the making of future corporate managers and they show considerable achievements in this educational process the level of corporate management and the related economic welfare of a society is after all in principle dependent on the quality of university education. However, contrary to these requirements, a typical style of management of a department is still formed on traditional academic principles which basically copy the model of appointing head academic officials as it was common during the Middle Ages; within this system, academic officials - managers in fact - are chosen according to certain specific criteria: a typical academic official is above all a highly erudite expert at his scientific discipline or an excellent pedagogue - yet the choice disregards his potential managerial education and skills. 


\subsection{Directive Interventions of Government}

The Ministries of Education in some Western countries have tried to accomplish relevant changes in this area at corresponding universities by directive implementation of "managerial" elements in a traditional university management and they achieved it through administrative means. However, the monitored results fail to be satisfactory: in a long-term perspective, these elements appear to manifest themselves as destructive elements destroying the former social mission of universities. Similar problems appear not only in European education environment but also in other cultures such are India, China and Australia (Colclough, 2010; Yi, 2011; Lewis, 2005).

On the one hand, changes that have to be implemented must comply with the requirements of today's globalizing world and, on the other hand, they are simultaneously bound to anticipate the expected long-term development of a society and the demands on education within a long-term perspective, at least until the year of 2020. It is therefore necessary to strive for a long-term sense-making nature of these changes and to search for the strategy ensuring the appropriate implementation of these changes in a traditional university environment that is expected to be actively resistant to these changes due to a large number of reasons.

\subsection{Traditional Managerial Characteristics of a Central European University}

The organization and position on the education market of Central European university differs from the systems applied in west countries. The managerial characteristics of a typical "stone" Central European university are as follows: (1) State makes financing of university budget. (2) Academician officials are elected by academic community - not designated by the government. (3) Access of students to education on not-private state higher schools is free of charge for everyone. (4) Academic staff is involved both in research and education - in many cases in the ratio "half and half".

The positions of professors and senior lecturers are shifted towards an upper age limit, which is consequently reflected also in age composition of leading departments and units at faculties. The Central European university education system is described as a highly bureaucratic institution even at the beginning of the $21^{\text {st }}$ century, in particular due to the heritage of the former Austro-Hungarian monarchy. Although several important reforms of university education were carried out in European countries in the course of the last twenty years, central authorities (occupying the positions of officials in individual states or political and administrative authorities within the EU) continue to decide about key areas of university life, either directly through regulations, or indirectly by means of budget. This powerful pressure has become even more intense upon the accession of the Czech Republic to the European Union in relation to the application of the ECTS standards and the funding of international mobility programmes where the allocated grants serve as an instrument of ensuring a top-down administrative management of a university. The bureaucratization of university management brought about by state bodies consequently leads to the increase in administrative workload both in these bodies and at universities. Universities have to respect all legal regulations and public notices as any production enterprise (lawful environment for business, occupational safety, accounting, reporting etc.) and, in addition to it, the regulations resulting from its specific position in the given state or in the EU.

One of the most pressing weak point identified in terms of the competition of Central European universities compared to the universities in the United Kingdom or the USA is the voting system by means of which academic officials are elected into their positions for a single and a relatively short term of three - four years. This system inevitably leads to the disruption of the "memory of an organization" as well as to the violation of its continuous development. The voting system is carried out in a way that would be unthinkable in any production enterprise. The choice and the election of officials are done not by professionals - specialists in human resources management - but by the whole academic community or a body elected for such a vote - an academic senate. The elected officials are most commonly experts at their professions but they are hardly ever equipped with managerial skills or they endeavour to achieve managerial education only before they are elected or in the course of their term of office. The result is the loss of a continuous "know-how" with respect to university management. The survey carried out in relation to this situation revealed a surprising fact that the majority of academic officials occupying even the highest positions in the managements of renowned universities felt no need of organizational learning in the field of management (Meister-Scheytt, 2005; Tarbini, 2010). This situation would change if the term of office of chief academic officers would be extended, for example to double. Then the elected officials could apply better use of their experience and knowledge gained during the active management of the institution. But this is not the intention of the Ministry, today.

However, the Central European universities (German, Austrian, Czech, Hungarian, Polish,...) have managed to survive this system, especially thanks to the academic environment where an elected official has only the best 
professional advisers at his disposal. Nonetheless, as the authors of the quoted sources state unanimously, harsh competition and the acceleration of changes will necessitate that academic officials would educate themselves in managerial professions voluntarily and in the interest of the respective university.

Therefore, in spite of the fact that the amendments of legal regulations as well as the revisions of existing rules allow universities to enjoy more or less high degree of autonomy in decision-making and in the assertion of their own idea of their future development, the existing and rather ponderous traditional forms of university organizational structure and its management do not encourage the desired development. Newly-established private universities do not seem to be burdened with the traditional forms, which enables them to adapt more easily to the new market environment.

If classic stone universities are to succeed in tackling the new challenges of education they have to ensure swift transformation of their routine and deep-rooted forms of management and to adapt them to new conditions: development of internationalizations, implementation of new technologies, knowledge-oriented university education, lifelong education and entrepreneurship in the development and transfer of new technologies.

\section{Approaches to the Change of University Organizational Structure}

\subsection{Understanding of Changes}

The necessity to change the organizational structure of an institution of higher education has been faced by more or less all universities. Changes implemented within the different forms of university management share many identical features with changes put into practice in production enterprises. However, changes related to the structure and the management taking place in a university environment differ considerably as far as particular conditions of such an environment are concerned:

- Graduate student success rate is generally manifested only after a very long time and there is therefore no clear feedback which would enable us to evaluate the quality of the carried out changes within a relatively short period of time.

- Changes are bound to respond to the future social development as well as to the social demand on education; however, it is a substantially unclear and ever-changing (and often even a highly turbulent) environment.

- Changes cannot be enforced by regulations as it is necessary to be accepted consensually by the given academic community.

- Changes are related to situations and problems which often fail to be understood and shared by individual academic officials and workers in the same way; even the most frequently used concepts such as "problem teaching", "integration of education", "knowledge-oriented curriculum", "practical training in educational process", "virtual education", "e-learning", "student-centred learning" are explained and interpreted by the members of academic staff in a different manner.

\subsection{Soft or Hard Decision Making-Descriptive or Normative Managerial Styles?}

Descriptive management model "organized anarchy" prefers the search for suitable forms of management and strategies using the trial and error method. This approach looks for as much as possible alternatives of solution and ideas which then serve as the source for discussions taking place at higher levels. Although this model, named ironically a "garbage can" model, seems to be of no use for a scientific and a knowledge-based workplace - for a university - it would be much surprising to us if we took a closer look at its management mechanisms at lower levels since we would find out that this model offers a proper characterization of contemporary situation at a great number of university workplaces. The descriptive model presented by Cohen and Marc (Cohen, 1986) most typically involves organizations which do not define any fixed goal.

This attitude may bring profit to organizations with stable environment. It in fact concerns a heuristic attitude as it may produce a great many ideas, themes and solutions. In theory, the methods based on random solution search (Monte Carlo methods) seem to correspond to this approach. Stable universities such as Harvard or Princeton whose position on education market is independent of globalization as well as of any other factors and which employ only the most excellent workers may find this hotbed of opinion substantially inspiring.

Normative management model is based on reporting, mutual communication among subsystems e.g. departments and processing of obtained data. If descriptive model can be considered as "soft" approach to decision making in case of normative model we deal more with hard data and information. Here, the proper functioning of an institution does not depend on the way the organization subsystems are arranged administratively but more likely on the way the quality of communication is ensured (Baecker, 2000). We have learned from practice that the universities having an organizational structure in the form of classic faculties and departments and disposing of a 
smaller number of workers prove to be functioning equally well as the universities divided into institutes with a great number of variously specialized experts and pedagogues.

\section{System Approach in Terms of Complexity}

\subsection{Complexity of Behaviour}

Enterprises and institutions tend to give a particular focus in their activities on a single area e.g. economy, production, education, law, ethics and morality, religion, politics, culture, science, art etc. Universities, on the contrary, cover many areas in their entirety if not even all of them. This situation further strengthens the argument that the processes involving the change in university structure and management should be understood as a major issue instead of being underestimated as a trivial matter. Although universities are formally oriented solely to education, science and research, they as well participate, either directly or indirectly in other areas of social activities. This direct participation of universities is seen as educational activities or the engagement of universities in scientific research including immediate connection with practical application. In terms of indirect involvement of universities it is important to note that they take part in other areas as autonomous entrepreneurial subjects as well and that they often run their own economy, production, services and consultancy. It is not insignificant that universities also get involved in social and cultural activities (Meister-Scheytt, 2005).

The complexity with respect to the content of university activities requires the existence of corresponding forms enabling the implementation of the given content. There we meet with paradoxes typical for university environment. Although university tuition provides a university pedagogue with creative freedom as far as the content of education is concerned, it simultaneously binds him to take part in some research work. A university pedagogue is thus bound to cope with at least two professional qualifications which are rather counter-productive when taking into account his employment - it concerns:

- knowledge acquisition, i.e. methodology, methods and technologies of research work,

- pedagogy, i.e. methodology, didactics and technique of pedagogical activity.

On the one hand, if a university pedagogue devotes himself to one of these activities, e.g. to tuition, it most probably prevents him and keeps him from his scientific work and scientific study. On the other hand, if he concentrates his capacities on the solution of a scientific problem, his duty of tuition may become an unpleasant delay and distraction as for his determination to pursue scientific work.

The increase in the numbers of students results in the situation when university workers begin to choose their specialization either in the area of research, or in tuition. It has become a typical phenomenon occurring upon the establishment of the so-called "mass university". However, it means no good for universities - it is linked with the separation of science and tuition and the tuition is no longer provided by a university pedagogue but only by a university teacher.

The university plays often the role of public and private universities in a society. From a certain perspective it is conceived as a public institution and is accordingly supported by state in return. In aspects concerning the research it behaves more likely as a private entity.

\subsection{Identification of Problems}

The point of departure when intending to search for new strategies of development as well as for appropriate organization of an institution and its style of management is believed to be an analysis of the needs and sources of such an institution. Expert studies imply that this process shares some features common to both aspects: it is very difficult if not even impossible to gather relevant information and opinions among one's own colleagues. It is possible to trace the following attributes (Gioia, 1996; Havlicek et al., 2007):

There are ideas, mental models and maps of future development and desired changes in workplaces but they are formulated only with great difficulty. It presents a difficult and a highly complicated process when higher management of the university is trying to find out this information directly from the persons concerned - it is often necessary to get this information from external sources, by a sort of detour, and it may require to use even various sophisticated methods of inquiring and more or less anonymous observation and monitoring. The smaller the workplace and the longer the period workers know each other, the more difficult it is to implement reforms and changes aiming to ensure the professionalization of activities. These workplaces experience the lingering presence of deep-rooted patterns of relationships and algorithms of solutions related to both personal and expert problems.

Each higher manager knows well that the attention paid to the given subject, discussion length and one's absorption in the problem concerned tends to have inverse relationship with the importance of the relevant theme. 
Participants devote too much of their attention to problems that are irrelevant and not related to the given subjects such as smoking in the workplace, location of offices, parking, laboratory equipment etc. These and similar subjects are then mixed up with discussions approaching some other and more serious issues. Academics are also self-cantered and obstinate.

Although academic community is able to find consensus as for the necessity to implement changes in the content and the focus of the given workplaces as well as in the definition of new goals, strategies and priorities, they are rather reluctant to hear that these changes usually require different organizational structure and style of management.

\subsection{Competition among Universities}

The competition within the universities has driven higher quality of education. The competitive behaviour of an university inside which academicians compete for the best faculty, the best students, the best papers, the highest external resources and reputation, may create an environment that demands excellence. On the other hand, it also may create an Darwinian "winner-take-all' ecosystem in which the strongest and wealthiest faculties have become predators, raiding the best faculty and students of the less generously supported and more constrained public universities and manipulating federal research and financial policies to sustain a system in which the rich get richer and the poor get devoured (Duderstadt, 2000; Duderstadt , 2004).

\section{Networked University}

Universities are believed to change their structure and form of management in order to conform to the changeable environment on education market as well as the ever-changing requirements within social environment. These days, it is possible to identify several more or less well functioning styles of management and the corresponding forms of organizational structures of the given university. Besides the existing forms there are also model forms which have not yet become deeply rooted in practice though they represent plans embracing considerably realistic possibilities.

Similarly, it is possible to encounter the name of "network university". In this case, analogously as in an enterprise, particular parts of a university become interconnected as well as they integrate within the university global environment, which is again achieved through communication channels.

It is impossible to find an adequate and a simple Czech equivalent when trying to translate the English terms of "network organization" or "network university" and similar terms of "virtual organization" or "virtual university" are thus used instead. The concept of a networked/virtual organization/university will therefore further on refer to an organization/university that has its internal structure interconnected with objects and subjects situated within the economic, social and political environment, in particular through communication networks and communication technologies.

A virtual university should function as a reversed alternative to a classic historical type of university, i.e. it should be a) democratic with the distribution of powers, b) highly flexible, c) swiftly and flexibly responding to incentives coming from the surrounding environment, d) open and cooperating with the surrounding educational environment (Lewis et all., 2005)..

The corporate as well as the entrepreneurial style of management applying the progressive implementation of ICT technologies allow for the creation of a type of virtual university ("network university") that is believed to represent the best scheme of management for such a complex institution like university.

Although the creation of a "virtual university" is in most cases the final objective of transformations pursued by many universities, the results which would prove its real functioning in practice have not yet been substantially confirmed. As McNay (McNay, 1995) argues in his study, university organization structure undergoing the process of transformation more likely tends to favour the determination of powers and autonomies that are to be transferred to lower units rather than taking actions leading to centralization. Based on the acquired data, he concludes, paradoxically enough, that the transformation into a virtual university is necessarily accompanied by the increase in bureaucratic processes and the strengthening of the "top-down" principle of management. Moreover, it is often the case that it is "network technology" that is built instead of the originally intended "network university".

The existing experience thus seems to assume more favourable approach to hybrid forms of universities and their implementation should occur on a simultaneous basis rather than having a sequential step by step character, which may lead to gradual increase in administrative load and the strengthening of the centres of management to the detriment of the determination of powers and autonomies granted to lower units. 
On the one hand, consistent employment of ICT technologies within the organizational type of a "virtual university" enables the determination of both powers and responsibilities from the centre up to individuals. On the other hand, it allows the centre to have a thorough and an unprecedented opportunity to control the quality as well as to supervise the delimited activities.

The use of ICT in our life appears to us as the progress and the good but we are paying a high price for it. In ancient Greece, the balance between man and nature ensured goddess Hybris: if one took something from nature, Hybris immediately compensated the losses to ensure equilibrium between nature and man. And so a man exploiting ICT unwisely - can easily become an object of manipulation and brainwashing. Never in history has been manipulating people so easy and effective. To prevent this, universities must increase the emphasis on humanitarian education, more focus on aesthetic education, strengthening the personality of their students. Humanization of the curriculum even at technical schools should be required future program.

\section{Conclusion}

One of the most eloquent critic of the concept of a "network university", David Noble, American professor, considers network education to represent the regress to assembly lines created by Ford (Bata Shoes). The way Ford produced automobiles (and analogically Bata his shoes) resembles the production of uniform and standardized university graduate students, argues Noble in his essay "Digital Diploma Mills" (Noble, 1998). The ICT technologies fail to provide professors with more freedom and space in their pedagogical process but it makes them assume the role of a manufacturer of students that are produced by universities as a semi-finished products. Education thus ceases to be a service as it concerns more likely the production of commodities, pedagogy becomes reduced to a mere recipe and a teacher is transformed into a technician, a craftsman or maybe into a laboratory worker whose only task is to follow the production procedures. A teacher loses his autonomy and he gradually becomes only a puppet of more or less anonymous administrative apparatus. Noble is not at all the only critic of this conception. Zuboff (Zuboff, 1998) introduces the idea of an electronic panopticon and Lyon (Lyon, 2007) talks about oppressive and even almost despotic environment which may occur due to the pressure of technology in a free academic environment accustomed to free and prudent as well as non-technocratic and non-algorithmic decision-making. The analysis of administrative load concludes, based on the gathered data, contemporary development has already proved an obvious non-linear growth of administration (Harper, 2005; Shutt, 2005).

Duderstadt (Duderstadt, 1999; 2003; 2009) recommends to organize virtual forms of education. The form of "Nika approach" to higher education means that a university will be bound to make strict distinction between the intellectual content of its activity and the objects realized out of it in the form of virtual tuition on education market. In other words, universities will begin to apply broad diversification of their activities in order to preserve and maintain the "nika" of their environment as an added value or as a standard part of their sustainable development strategy. It therefore basically concerns the idea of creating the "UNIVERSITY within an university"; capital letters in the first word are important - they represent an excellent unit existing within a university that will, independently of the mass production of students and the commercialization of education, continue to keep traditional values for the selected groups of students and teachers. A highly intellectual and scientifically proficient centre in a mass-university will ensure its further development, offer small-scale and highly specialized fields of study for the best students and teachers, and maintain traditions.

\section{References}

Baecker, D. (2000). Why Systems? Theory, Culture and Society, 18(1), http://dx.doi.org/10.1177/026327601018001005

Cohen, M. D., \& March, J. G. (1986). Leadership and Ambiguity. Harward Business School Press.

Colclough, C., De, A. (2010). The Impact of Aid on Education Policy in India. International Journal of Educational Development, 30(5), 497-507. http://dx.doi.org/10.1016/j.ijedudev.2010.03.008

Duderstadt, J. J. (1999). Positioning the University of Michigan for the New Millennium: A Case Study in University Transformation. University of Michigan. ISSN/ISBN 978-0-472-11091-9.

Duderstadt, J. J. (2000). A University for the 21st Century. University of Michigan Press. ISSN/ISBN 978-0-472-11091-9.

Duderstadt, J. J. (2004). Higher Learning in the Digital Age: An Update on a National Academies Study. The University of Michigan. Educause Denver, Colorado. ISSN/ISBN 978-1-573-56520-2. 
Duderstadt, J. J. (2009). Aligning American Higher Education with a Twenty-First-Century Public Agenda. Examining the National Purposes of American Higher Education: A Leadership Approach to Policy Reform. Higher Education in Europe, 34(3-4), 347-366. http://dx.doi.org/10.1080/03797720903355612

Duderstadt, J. J., Atkins, D. A., \& Houweling, D. E. (2003). Higher Education in the Digital Age. Oryx Press. ISSN/ISBN 978-1-573-56520-2.

Gioia, D. A., \& Thomas, J. B. (1996). Identity, Image, and Issue Interpretation: Sensemaking during Strategic Change in Academia. Administrative Science Quarterly, 41(3), 370-403.

Harper, F. (2006). University Quality Assessment. A Report of the Assessment Carried Out in the Period October 2005 to February 2006. Internal Publication. Prague. CULS.

Havlicek, J. (2008). Harmonisation of National and European Qualifications Framworks. Prague. CULS.

Havlicek, J., Hron, J., \& Ticha, I. (2006). Knowledge Based Higher Education. Agricultural Economic, 52(3), 107-116.

Havlicek, J., \& Ticha, I. (2007). Knowledge Transfer. Agricultural Economic, 53(12), 539-544.

Lewis, T., Marginson, S., \& Snyder, L. (2005). The Network University? Technology, Culture and Organisational Complexity in Contemporary Higher Education. Australia: Monash University.

Lyon, D. (2007). Surveillance Studies: An Overview. New York: John Wiley. ISSN/ISBN 978-07456-3591-0.

Mcnay I, (Ed.). (1995). From the collegia academy to corporate enterprise: The changing cultures of universities. Buckingham: Open University Press; 1995.

Meister-Scheytt, C., \& Scheytt, T. (2005). The Complexity of Change. Higher Education Quarterly, 59(1). http://dx.doi.org/10.1111/j.1468-2273.2005.00282.x

Noble, D. F. (1998). Digital Diploma Mills: The Automation of Higher Education. Science as Culture, 7(3), 355-368. http://dx.doi.org/10.1080/09505439809526510

Shutt, J. (2005). The New Long Term Plan and Priorities of the Development at the Czech University of Agriculture Prague - Aims and Methodology of Implementation. Prague: CULS.

Tarabini, A. (2010). Education and Poverty in the Global Development Agenda: Emergence, Evolution and Consolidation. International Journal of Educational Development, $204-212$. http://dx.doi.org/10.1016/j.ijedudev.2009.04.009

Yi, L. (2011). Auditing Chinese Higher Education? the Perspectives of Returnee Scholars in an Elite University. International Journal of Educational Development, 399-508. http://dx.doi.org/10.1016/j.ijedudev.2011.03.003

Zuboff, S. (1998). In the Age of the Smart Machine: The Future of Work and Power. New York. Basic Books. ISSN/ISBN 10-0465032125. 